\title{
Age-related differences in factors associated with the underuse of recommended medications in acute coronary syndrome patients at least one year after hospital discharge
}

Hong Jin, Chengchun Tang, Qin Wei, Long Chen, Qin Sun, Genshan Ma ${ }^{*+}$ and Naifeng Liu ${ }^{\dagger}$

\begin{abstract}
Background: Few studies have evaluated age-related predictors associated with the underuse of medications in patients with coronary heart disease (CHD). The objective of this study was to identify age-related differences in the factors associated with the underuse of recommended medications in patients diagnosed with acute coronary syndrome (ACS).

Methods: From August 2009 to April 2011, we recruited 469 consecutive ACS patients from a cardiac center at a university hospital. We divided the patients into older (65 years of age and older, $\mathrm{n}=202$ ) and younger groups (younger than 65 years of age, $n=267$ ). Data on socio-demographic characteristics, depressive symptoms, and medication use were obtained from a telephone survey administered 18 to 24 months after hospital discharge. Additionally, we asked the patients to provide reasons for not taking their medications.

Results: A significantly increased underuse of medication was noted in older patients compared with younger patients, including aspirin ( $24.8 \%$ vs. $37.1 \%, p=0.005)$, beta-blockers ( $20.3 \%$ vs. $34.8 \%, p=0.001)$, ACE inhibitor/ angiotensin receptor blockers ( $27.2 \%$ vs. $36.7 \%, p=0.030$ ), and statins ( $21.8 \%$ vs. $29.6 \%, p=0.005)$. Among older patients, the factors associated with the underuse of medications included low education level (odds ratio [OR], 3.93), greater number of comorbidities (OR, 1.64), and total number of discharge medications (OR, 1.31). The reasons provided by older patients for not taking medication included the fact that the medication was considered to be non-essential and the large number of medications. Among younger patients, low income $(O R, 3.97)$ and depression $(O R, 2.62)$ were predictors for underuse of medication, and the reasons provided for not taking medications included high costs and the fear of adverse effects.
\end{abstract}

Conclusions: At least one year after ACS hospital discharge, the underuse of recommended medications is related to low education level, comorbidities, and the total number of discharge medications in elderly patients, whereas underuse in younger patients is associated with low income and depression. The disparities related to these different predictors may have implications for age-related interventions targeting secondary preventions in CHD patients to improve their use of medication.

Keywords: Medications, Secondary prevention, Age factors, Aged, Coronary heart disease

\footnotetext{
* Correspondence: magenshan@hotmail.com

${ }^{\dagger}$ Equal contributors

Department of Cardiology, Zhongda Hospital, Medical School of Southeast

University, 210009 Nanjing, Jiangsu, China
} 


\section{Background}

Coronary heart disease (CHD) is the leading cause of morbidity and mortality in China [1-3]. Urbanization, industrialization, and population aging have resulted in a rapid and significant increase in the prevalence of CHD in recent decades [1]. Unstable angina (USA), Non-ST segment elevation myocardial infarction (NSTEMI), and ST-segment elevation myocardial infarction (STEMI) are common manifestations of acute coronary syndrome (ACS) and are major causes of hospitalizations [4-6]. Conversely, this rate has decreased over the last 3 decades because of the attention given to coronary risk factors and improvements in clinical management $[5,6]$. Therefore, efforts should be refocused on secondary prevention. The secondary prevention of CHD involves managing both lifestyle factors and physiologic parameters, often with medications. It is well accepted that adequate treatments with multiple evidence-based medications and vigorous control of major risk factors in CHD patients are costeffective secondary strategies $[7,8]$. More than $40 \%$ of the recent decline in CHD mortality has been attributed to evidence-based medications [9]. The recommended medications for patients who have previously experienced an ACS episode include the concurrent use of lipidlowering agents, antiplatelet medications, beta-blockers, and angiotensin-converting enzyme inhibitors (ACEI) or angiotensin II receptor blockers (ARB) [10,11].

Despite the large amount of evidence supporting the use of recommended medications and the development of public policies, which have led to significant improvements in ACS management and its consequences in recent years, the underuse of optimal cardioprotective medications is prevalent among CHD outpatients and is associated with a broad range of adverse outcomes, including all-cause and cardiovascular mortality, cardiovascular hospitalizations, and revascularization procedures [12-14]. However, in many developed countries, the rate of recommended medication use is reportedly low $[9,13,15]$, particularly for older patients [16]. Several studies have suggested that agerelated differences in the use of secondary medical preventions are a widespread phenomenon among CHD patients and that older patients are less likely to take recommended medications [16-18]. However, few studies have attempted to explain the age-related differences in the underuse of these secondary prevention medications based on sociodemographic factors and clinical characteristics or to evaluate the differences in terms of the reasons why patients did not take their medications.

We performed a long-term observational study with the following objectives: 1 ) to better characterize the underuse of recommended medications for secondary prevention in Chinese ACS patients at least one year after hospital discharge; 2) to determine whether age is associated with the underuse of medications in these high-risk CHD patients; and 3) to identify differences in the factors associated with the underuse of recommended medications between age groups. Additionally, we explored the patients' reasons for not taking their recommended medications.

\section{Methods \\ Study population}

From August 2009 to April 2011, consecutive ACS patients were selected from a cardiac center at a university hospital, located in Nanjing. Diagnosis of ACS is based upon symptom history, clinical presentation, electrocardiogram ST-segment changes, and enzyme elevation. All participants provided full written informed consent, and the study was approved by the Committee of Clinical Investigation at Southeast University School of Medicine. The following exclusion criteria were applied: age older than 85 years, age younger than 18 years, severe hearing impairment, unintelligible speech, lack of cooperation, delirium or severe dementia, illness that interfered with participation, overt psychiatric illness, administration of all medications by a caregiver, and no telephone number. Given that the purpose of our study was to assess the underuse of recommended medications in ACS patients at least one year after discharge, patients were also excluded if they suffered from an ACS episode within 12 months and if they participated in other clinical trials.

In total, 697 eligible patients were identified during the study period. Of these patients, 118 were excluded; 17 patients died before the survey was administered; 15 patients were older than 85 years of age; 54 patients participated in other clinical trials; 9 patients had a psychiatric illness or cognitive decline, and 23 patients were hospitalized for a recurrent acute coronary event during the 12-month period before the survey was administered. Of the 579 patients included in the study, 63 patients were unavailable for follow-up, and 23 patients did not complete the telephone review. An additional 24 patients refused to respond to a telephone survey. Hence, a total of 469 patients were included in this analysis (Figure 1). We use 65 years of age and older as the definition of an older individual because most countries have accepted this definition of old age. With regard to anthropometric, socioeconomic, and clinical characteristics, no statistically significant differences were noted between the responders and non-responders.

\section{Design and data collection}

While still hospitalized following their procedures, the patients were approached by a researcher who assessed their eligibility for study enrollment. Baseline medications were collected using medical charts and electronic medical records. The collected data included patient demographics, past medical history, clinical characteristics, comorbidities, inpatient treatment, medications prescribed at the time of 


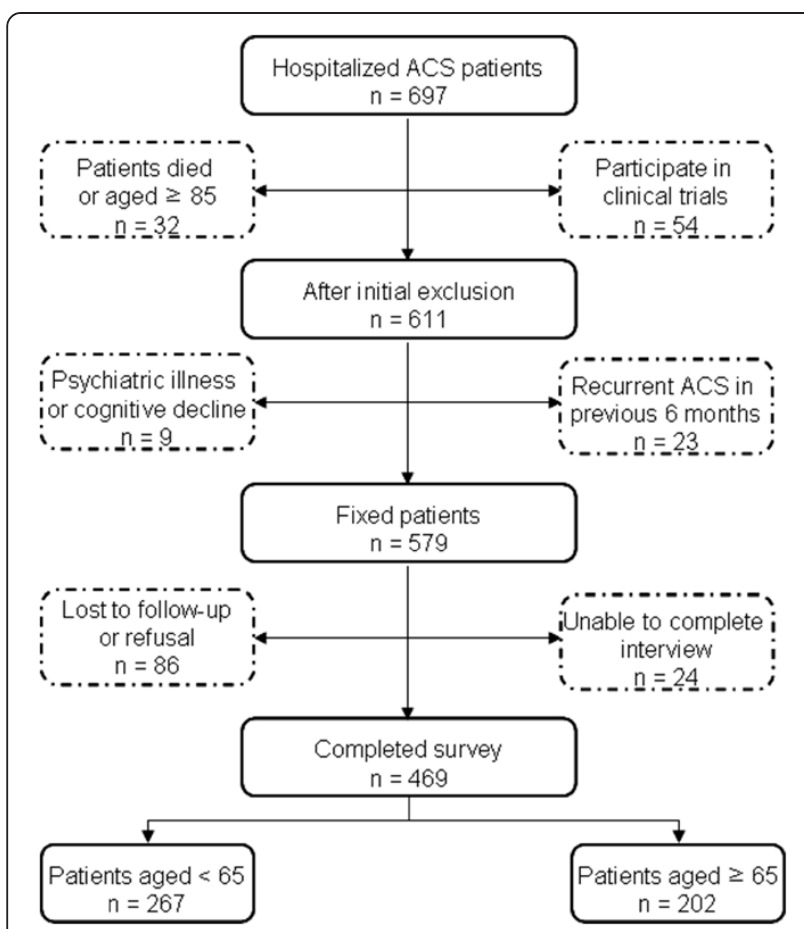

Figure 1 Recruitment flowchart. ACS, acute coronary syndrome.

discharge, and in-hospital outcomes. The recommended medications prescribed at the time of discharge, including aspirin, beta-blockers, statins, and ACEI/ARB, were obtained from the medical records. ACEI and ARB were grouped as a single variable because they are both used in the treatment of hypertension and congestive heart failure, and ARB is generally administered to patients who are intolerant of ACEI. The variable "total number of discharge medications" was the sum of all chronic medications mentioned by the patient at the time of discharge from the hospital.

During the study period, follow-up information was obtained from patients via telephone surveys conducted by trained interviewers approximately 18 to 24 months after discharge. The purpose of this survey was to document the occurrence of secondary cardiovascular events, hospitalizations, and scheduled or unscheduled outpatient cardiologist visits between the time of discharge and the telephone survey. We also assessed current medication use and depressive symptoms. At least 3 attempts to contact patients were made at various times of the day. For the purpose of this analysis, the length of time in days from the date of discharge to the date of telephone contact (interim period time) was taken as the number of months post discharge.

The telephone questionnaire focused on the following points. The first section included patient baseline characteristics, such as age, sex, educational level, marital status, income, living situation, smoking, alcohol use, medical history, and depressive symptoms. To evaluate the presence and severity of depressive symptoms, we administered the well-validated 9-item Patient Health Questionnaire (PHQ) [19]. Higher scores indicated more severe depressive symptoms. Our primary predictor variable was a single question regarding the treatment status of aspirin, statins, betablockers, and ACEI or ARB. Information regarding medication use was obtained by asking the patients to provide their medication bottles and to respond to the question, "What medications do you take now?" If the patients replied, "none," the reasons for not taking the medications were explored. To perform this assessment, the patients were asked, "Which one of the following is the reason for not taking it?" The patients were prompted with possible options, including being unable to afford the cost of the medications, considering the medications to be nonessential, having been prescribed too many medications, being concerned about adverse effects, and suffering side effects. The patients were asked to choose their reasons for not taking the medications. More than one reason could be recorded.

\section{Statistical analyses}

The data are presented as the mean \pm standard deviation for normally distributed data or as the median (interquartile range) for skewed continuous variables. We conducted comparisons of continuous variables using Student's $t$-test or the Mann-Whitney $U$ test. The chi-squared test was used to compare categorical variables between the two groups. Associations between variables of interest and the underuse of medication were assessed using logistic regression. Significant univariate predictors were included in multivariate logistic regression analysis. We included the following 9 covariates in the model: age, gender, education, insurance, income, comorbidities, PHQ scores, number of medications at the time of discharge, and outpatient cardiologist visit from the time of discharge. We performed statistical analyses using SPSS software 16.0 (SPSS Inc., Chicago, IL, USA). All tests were two-sided. We considered $\mathrm{p}<0.05$ to be statistically significant.

\section{Results}

Comparison of the anthropometric, socioeconomic, and clinical characteristics of patients in the two age groups is presented in Table 1 . The older patients were more likely to live alone and were less likely to have completed senior high school or higher. Compared with the younger group, employment in the older age group was significantly lower. Established comorbidities (congestive heart failure, diabetes mellitus, dyslipidemia, stroke, chronic renal failure, and chronic obstructive pulmonary disease) were more prevalent in the older age group. Compared with the older group, the younger patients had significantly higher PHQ scores. The number of discharge medications prescribed to 
Table 1 Characteristics of the study patients based on age group

\begin{tabular}{|c|c|c|c|c|}
\hline & Overall $(n=469)$ & $\begin{array}{c}65 \text { years of age } \\
\text { and older }(n=202)\end{array}$ & $\begin{array}{c}\text { Younger than } 65 \text { years } \\
\text { of age }(n=267)\end{array}$ & $p$ \\
\hline Age, years & $62.4 \pm 9.7$ & $71 \pm 5$ & $56 \pm 6.9$ & $<0.001$ \\
\hline Gender, female, n (\%) & $142(30.3)$ & $67(33.2)$ & $75(28.1)$ & 0.264 \\
\hline Married & $442(94.2)$ & $187(92.6)$ & $255(95.5)$ & 0.229 \\
\hline \multicolumn{5}{|l|}{ Educational level } \\
\hline Junior high school or lower & $166(35.4)$ & $91(45.0)$ & $75(28.1)$ & \multirow[t]{3}{*}{$<0.00$} \\
\hline Senior high school & $198(42.2)$ & $86(42.6)$ & $112(41.9)$ & \\
\hline University/college & $105(22.4)$ & $25(12.4)$ & $80(30.0)$ & \\
\hline Manual laborer & $48(10.2)$ & $26(12.9)$ & $22(8.2)$ & 0.101 \\
\hline Employed & $178(38)$ & $7(3.5)$ & $171(64)$ & $<0.001$ \\
\hline \multicolumn{5}{|l|}{ Income (Chinese yuan/month) } \\
\hline $1,200-3,000$ & $248(52.9)$ & $156(77.2)$ & $92(34.5)$ & \multirow[t]{3}{*}{$<0.001$} \\
\hline $3,000-5,000$ & $166(35.4)$ & $27(13.4)$ & $139(52.1)$ & \\
\hline$\geq 5,000$ & $55(11.7)$ & $19(9.4)$ & $36(13.5)$ & \\
\hline Basic medical insurance $^{*}$ & $391(83.4)$ & $162(80.2)$ & $229(85.8)$ & 0.109 \\
\hline Live alone & $29(6.2)$ & $20(9.9)$ & $9(3.4)$ & 0.004 \\
\hline Currently smoking & $111(23.7)$ & $45(22.3)$ & $66(24.7)$ & 0.538 \\
\hline Regular alcohol use & $30(6.4)$ & $12(5.9)$ & $18(6.7)$ & 0.726 \\
\hline Depressive symptoms (PHQ score) & $4(2-7)$ & $4(2-6)$ & $5(3-7)$ & 0.005 \\
\hline No. of diseased vessels & $1(1-2)$ & $1(1-2)$ & $1(1-2)$ & 0.107 \\
\hline \multicolumn{5}{|l|}{ Comorbidities } \\
\hline Congestive heart failure & $37(7.9)$ & $27(13.4)$ & $10(3.7)$ & $<0.001$ \\
\hline Diabetes & $103(22.0)$ & $57(28.2)$ & $46(17.2)$ & 0.004 \\
\hline Hypertension & $262(55.9)$ & $122(60.4)$ & $140(52.4)$ & 0.086 \\
\hline Dyslipidemia & $84(17.9)$ & $49(24.3)$ & $35(13.1)$ & 0.002 \\
\hline Cardiac dysrhythmias & $31(6.6)$ & $18(8.9)$ & $13(4.9)$ & 0.081 \\
\hline Stroke & $27(5.8)$ & $17(8.4)$ & $10(3.7)$ & 0.032 \\
\hline Any previous revascularization & $36(7.7)$ & $21(10.4)$ & $15(5.6)$ & 0.054 \\
\hline Chronic renal failure & $38(8.1)$ & $24(11.9)$ & $14(5.2)$ & 0.009 \\
\hline COPD & $29(6.2)$ & $19(9.4)$ & $10(3.7)$ & 0.012 \\
\hline Gastrointestinal disease & $48(10.2)$ & $27(13.4)$ & $21(7.9)$ & 0.052 \\
\hline Others & $45(9.6)$ & $29(14.4)$ & $16(6.0)$ & 0.002 \\
\hline In-hospital treatment (PCI/CABG) & $444(94.7)$ & $190(94.1)$ & $254(95.1)$ & 0.609 \\
\hline Time between discharge and follow-up survey, months & $19.5 \pm 2.6$ & $19.3 \pm 2.6$ & $19.7 \pm 2.6$ & 0.161 \\
\hline Number of outpatient cardiologist visits since hospital discharge & $7(5-9)$ & $6(4-8)$ & $8(6-10)$ & $<0.001$ \\
\hline Rehospitalization since discharge ${ }^{\#}$ & $0(0-1)$ & $0(0-1)$ & $0(0-1)$ & 0.092 \\
\hline \multicolumn{5}{|l|}{ Medication use at discharge } \\
\hline Aspirin & $445(94.9)$ & $188(93.1)$ & $257(96.5)$ & 0.121 \\
\hline Beta-blocker & $420(89.6)$ & $175(86.6)$ & $245(91.8)$ & 0.072 \\
\hline Statin & $414(88.3)$ & $172(85.1)$ & $242(90.6)$ & 0.067 \\
\hline ACE inhibitor/ARB & $319(68.0)$ & $135(66.8)$ & $184(68.9)$ & 0.632 \\
\hline Number of prescribed medications ${ }^{\S}$ & $6(5-10)$ & $8(5-12)$ & $5(4-7)$ & $<0.001$ \\
\hline
\end{tabular}

Data are represented as the number (\%) of patients; ${ }^{*}$ medical insurance provided by the government; STEMI, ST segment elevated myocardial infarction; NSTEMI, non-ST segment elevated myocardial infarction; COPD, chronic obstructive pulmonary disease; CABG, coronary artery bypass graft; $\mathrm{PCl}$, percutaneous

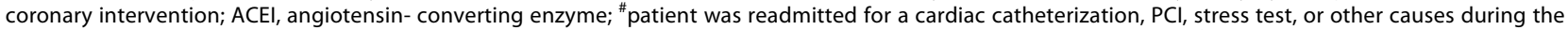
interim follow-up period from hospital discharge to the date of the follow-up survey; ARB, angiotensin receptor blocker; ${ }^{5}$ the number of patients using prescribed medications, including non-recommended medications. 
older patients was greater than that prescribed to younger patients. The younger patients were more likely to see physicians on a regular basis compared with older patients. No between-group differences were observed in terms of marital status, insurance, smoking, number of diseased vessels, management strategies, and rehospitalization from the time of discharge.

Every patient in the cohort was prescribed at least one recommended medication at hospital discharge. The majority $(89.3 \%)$ of the population was prescribed three or more recommended medications (e.g., aspirin, betablockers, statin, and ACEI/ARB) at hospital discharge (Table 1). The rate of prescribed recommended medications at hospital discharge was similar between the two age groups (Table 1). The number of patients using 10 or more prescribed medications, including non-recommended medications, at the time of discharge was larger in older patients than in younger patients $(43.6 \%$ of those 65 years of age and older and $12.4 \%$ of those younger than 65 years of age) $(\mathrm{p}<0.001)$.

At the time of the follow-up survey, 39.7\% patients were not taking any recommended medications $(51.5 \%$ in the older group and $30.7 \%$ in the younger group). Figure 2 shows the rate of recommended medication use for the total number of patients and for each age group at the time of the survey. Overall, the proportion of patients who continued to use aspirin, beta-blockers, ACEI/ARB, and statin therapy was $31.8 \%, 28.8 \%, 32.6 \%$, and $24.7 \%$, respectively. Significantly lower medication use was noted in older patients than in younger patients, including the use of aspirin $(24.8 \%$ vs. $37.1 \%, \mathrm{p}=0.005)$, beta-blockers ( $20.3 \%$ vs. $34.8 \%, \mathrm{p}=0.001)$, ACEI/ARB $(27.2 \%$ vs. $36.7 \%$, $\mathrm{p}=0.030)$, and statins $(21.8 \%$ vs. $29.6 \%, \mathrm{p}=0.005)$.

The reasons for not taking the recommended medications varied between age groups (Table 2). More older patients complained about taking too many medications ( $48.7 \%$ vs. $17.9 \%$ for aspirin, $40.5 \%$ vs. $10.9 \%$ for betablocker, and $39.2 \%$ vs. $8.9 \%$ for ACEI/ARB) or considered medications to be non-essential (36.4\% vs. $5.3 \%$ for statins, $32.7 \%$ vs. $12.6 \%$ for beta-blocker, and $37.8 \%$ vs. $7.7 \%$ for ACEI/ARB). Among younger patients, cost $(37.8 \%$ vs. $10.9 \%$ for statin, $23.0 \%$ vs. $6.0 \%$ for beta-blocker, and $29.0 \%$ vs. $6.1 \%$ for ACEI/ARB) and fear of adverse effects (31.5\% vs. $8.2 \%$ for aspirin, $37.4 \%$ vs. $7.7 \%$ for beta-blocker, and $43.2 \%$ vs. $7.4 \%$ for $\mathrm{ACEI} / \mathrm{ARB}$ ) were common reasons for not taking medications.

Overall, age was an independent predictor of medication underuse $(\mathrm{OR}=1.05,95 \% \mathrm{CI}, 1.02-1.08, \mathrm{P}=0.002)$, even after adjusting for gender, education, income, insurance, comorbidities, PHQ scores, and the number of medications at discharge. In subgroups, low educational level, more comorbidities, and high numbers of discharge medications exhibited an independent and a positive impact on medication underuse in older patients, whereas low income and higher PHQ scores were predictors for medication underuse in younger patients (Table 3). Additionally, an inverse relationship between older age and recommended medication use was noted in both groups (Table 3).

\section{Discussion}

Overall, the proportions of ACS patients who continued to use aspirin, beta-blockers, ACEI/ARB, and statins at least one year after discharge were 31.8\%, 28.8\%, 32.6\%, and $24.7 \%$, respectively. Despite the fact that the number of prescribed medications at hospital discharge was high for the ACS patients, the rate of medication use reduced obviously one year after discharge. The treatment rate of recommended medications in the present survey is low compared with that employed in Western countries [9] or other surveys in mainland China $[3,20]$. However, a comparison of these reports must be viewed with caution. Considerable differences exist between the present study and other studies, particularly with regard to the population selection criteria, ascertainment of medication use, and time points studied. Our study population

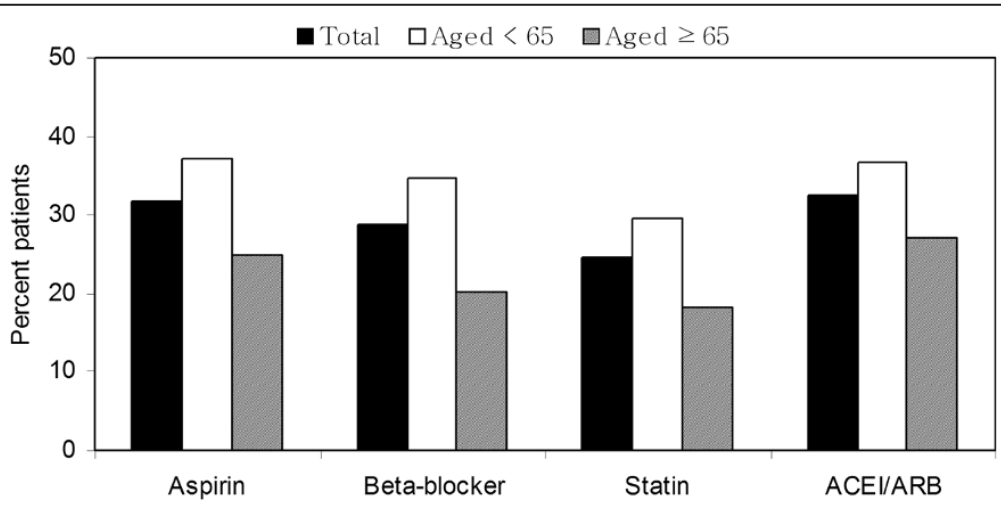

Figure 2 Percentage of patients taking recommended medications based on age at the time of the survey. (P-value: aspirin $=0.005$, beta-blockers $=0.001$, statins $=0.005$, angiotensin-converting enzyme inhibitor [ACEl]/angiotensin receptor blocker $[$ ARB $]=0.030$, between age groups) . 
Table 2 Reasons cited by patients who were not taking the recommended medications, by age group

\begin{tabular}{|c|c|c|c|c|c|c|c|c|}
\hline \multirow[t]{2}{*}{ Reasons } & \multicolumn{4}{|c|}{65 years of age and older } & \multicolumn{4}{|c|}{ Younger than 65 years } \\
\hline & Aspirin & Statin & Beta-blocker & ACEI/ARB & Aspirin & Statin & Beta-blocker & ACEI/ARB \\
\hline & \multicolumn{8}{|c|}{ n (\%) } \\
\hline Too expensive & $11(7.0)$ & $18(10.9)$ & $10(6.0)$ & $9(6.1)$ & $21(12.5)$ & $71(37.8)$ & $40(23)$ & $49(29.0)$ \\
\hline Too many medications & $77(48.7)$ & $47(28.5)$ & $68(40.5)$ & $58(39.2)$ & $30(17.9)$ & $18(9.6)$ & $19(10.9)$ & $15(8.9)$ \\
\hline Consider medications non-essential & $32(20.3)$ & $60(36.4)$ & $55(32.7)$ & $56(37.8)$ & $28(16.7)$ & $10(5.3)$ & $22(12.6)$ & $13(7.7)$ \\
\hline Afraid of adverse effects & $13(8.2)$ & $17(10.3)$ & $13(7.7)$ & $11(7.4)$ & $53(31.5)$ & $63(33.5)$ & $65(37.4)$ & $73(43.2)$ \\
\hline Side effects & $16(10.1)$ & $14(8.5)$ & $15(8.9)$ & $8(5.4)$ & $16(9.5)$ & $16(8.5)$ & $20(11.5)$ & $12(7.1)$ \\
\hline Others & $9(5.7)$ & $9(5.5)$ & $7(4.2)$ & $6(4.1)$ & 20 (11.9) & $10(5.3)$ & $8(4.6)$ & $7(4.1)$ \\
\hline
\end{tabular}

ACEI, angiotensin-converting enzyme inhibitor; ARB, angiotensin receptor blocker.

consisted of a selected sample of consecutive ACS patients at least one year after hospital discharge, whereas the study subjects in other reports were selected from outpatient departments [3], which appear to underestimate the treatment rates of these medications because the patients who discontinued treatment may not visit the outpatient departments of hospitals. Additionally, in prior investigations, a subsequent ACS episode occurred in most study patients within 6 months to 1 year [20]. According to American Heart Association (AHA) guidelines, dual antiplatelet therapy consisting of aspirin and a thienopyridine agent, such as clopidogrel, should be administered for at least a full year and perhaps even longer in cases of certain stent placements in patients without a major risk for bleeding [21]. Thus, Studying consecutive patients may explain why the patients in our study, whose recent ACS episodes occurred after one year, were less likely to receive the recommended medical therapies.

In agreement with a previous report [16], the older patients in our study reported significantly reduced uses of recommended medications, even after adjusting for other co-factors, such as total number of discharge medications, education, and income. More importantly, this study identified age-related disparities in the factors associated with the underuse of recommended medications in CHD patients.

Low education level is correlated with medication underuse in older patients. This finding agrees with other studies demonstrating that low education and low health literacy are correlated with medication non-adherence [9]. Low educational status may indicate limited financial resources for medications or may reflect lower health literacy. Makaryus et al. reported that $<50 \%$ of patients could list all their medications and even fewer could recall the purpose of their medications at the time of hospital discharge [22]. Patients often delay filling prescriptions and have difficulty understanding medication regimens after hospital discharge [23]. Similarly, we observed that the majority of elderly patients considered their medications to be non-essential or that they lacked knowledge of the medications. Ineffective

Table 3 Multivariate logistic regression models analysis for not taking any recommended medications at the time of the survey

\begin{tabular}{|c|c|c|c|c|}
\hline & \multicolumn{2}{|c|}{65 years of age and older } & \multicolumn{2}{|c|}{ Younger than 65 years } \\
\hline & OR $(95 \% \mathrm{Cl})$ & $p$ & OR $(95 \% \mathrm{Cl})$ & $\mathrm{p}$ \\
\hline Age (per year) & $1.12(1.02-1.22)$ & 0.015 & $1.11(1.03-1.19)$ & 0.008 \\
\hline \multicolumn{5}{|l|}{ Gender (vs. male) } \\
\hline Female & $0.32(0.13-0.79)$ & 0.013 & $0.95(0.35-2.58)$ & 0.921 \\
\hline \multicolumn{5}{|l|}{ Education (vs. senior high school or higher) } \\
\hline Junior high school or lower & $3.93(1.65-9.32)$ & 0.002 & $2.69(0.86-8.46)$ & 0.088 \\
\hline \multicolumn{5}{|l|}{ Income (vs. medium income or higher) } \\
\hline Low income & $0.58(0.22-1.51)$ & 0.264 & $3.97(1.47-10.75)$ & 0.007 \\
\hline \multicolumn{5}{|l|}{ Insurance (vs. basic medical insurance) } \\
\hline Lack of insurance & $2.65(0.89-7.86)$ & 0.080 & $2.58(0.75-8.85)$ & 0.131 \\
\hline Number of comorbidities & $1.64(1.12-2.39)$ & 0.011 & $0.85(0.39-1.84)$ & 0.686 \\
\hline PHQ scores & $0.97(0.87-1.08)$ & 0.570 & $2.62(2.03-3.38)$ & $<0.001$ \\
\hline Number of medications ${ }^{*}$ & $1.31(1.11-1.55)$ & 0.001 & $0.99(0.70-1.42)$ & 0.989 \\
\hline Number of outpatient cardiologist visits & $1.16(0.98-1.38)$ & 0.086 & $1.02(0.85-1.23)$ & 0.822 \\
\hline
\end{tabular}

"Number of prescribed medications at time of discharge; PHQ, Patient Health Questionnaire. 
communication between the primary care physician and $\mathrm{CHD}$ patients can further compromise a patient's understanding of his or her disease, its potential complications, and the importance of the prescribed medication [24]. Another possible explanation is that low education status may be associated with lower understanding of the benefits of continued medication use.

In the present study, cardiovascular-related comorbid conditions and other chronic illness were more prevalent in older patients. Conditions that are asymptomatic and chronic in nature and require long-term therapy are also associated with low medication use [9]. Older patients may have more severe diseases or comorbidities and were also more likely to be prescribed more evidencebased therapies. Polypharmacy continues to evolve, and new and synergic therapies for heart disease continue to be developed. A high number of concurrent medications were also a primary cause of medication underuse in elderly patients. Older patients more often reported not taking the recommended medications because of the large number of discharge medications. This result is consistent with a prior report indicating that as the total number of medications prescribed at the time of discharge increased, patient adherence to the cardiac regimen decreased [25]. This finding indicates that the complexity of the regimen can impact medication use. Thus, chronic disease management programs should consider all of the medications that patients are taking and reduce complexity by addressing multiple dosing frequencies whenever possible [26].

Among younger patients, high cost was an important reason for not taking medication. Cost issues have been identified as a major barrier to medication use [25,27]. These analyses have demonstrated that disadvantaged financial status, as indicated by monthly incomes, was strongly associated with low medication use. Despite the rapid development of initiatives in mainland China to improve health insurance coverage [28], treatment costs are likely to remain an important predictor of low treatment rates. Considerable out-of-pocket medical costs are even encountered by patients with basic health insurance coverage and are an even great issue for patients with long-term treatments based on polypharmacy. The cost associated with hospitalization and discharge medications represents an unanticipated expense that can serve as a substantial burden, particularly for younger patients on fixed incomes. Furthermore, younger patients often have children and elderly parents to support and homes to maintain. Thus, chronic illnesses and medical expenditures could significantly reduce the financial resources of households [29]. It is unsurprising that even employed and insured patients are unable to keep up with increasing costs. Our findings reveal a major barrier for the medical care of patients at high risk for developing CHD in mainland China. Younger patients, particularly low-income patients with limited access to medical insurance, as defined in this study, represent a large portion of the population of China. Clearly, improvements in medical care for high-risk younger CHD patients in China will depend on increasing the affordability of essential medications, which could be addressed by either increased access to medical insurance, reduced medical care costs, or increased income for younger patients.

Depression is widely associated with heart disease. One in three ACS patients meet the criteria for minor depression [30]. We noted that younger patients with higher PHQ scores, indicative of depression, were associated with medication underuse. Specifically, the development of ischemic heart disease and related events may produce more dissatisfaction, sadness, and disappointment in a younger patient compared with an older patient who has become accustomed to chronic illness. Depression has been established as a risk factor for morbidity and mortality in CHD patients [31] and can substantially affect medication use [32], which is an important confounder that must be monitored and measured. Even mild depression is sufficient to dramatically alter compliance with essential therapy. A study of patients with ACS found that the nonadherence rate in patients without depression was 15\% and increased to $30 \%$ in those with mild depression. Patients with moderate-to-severe depression were only slightly less adherent (37\%), which suggests that the presence or absence of depression is far more important for medication use than the degree of depression [32,33]. Based on these results, the mental health of patients contributes to the non-use of recommended medications. In contrast, depression improvements in cardiac patients were associated with improved medication use [34], indicating that the early diagnosis and treatment of depression is important in CHD patients.

Approximately $50 \%$ of the younger patients also reported being concerned about the adverse effects of their medications. The patients' perceptions of adverse effects contributed significantly to their decisions regarding medication use. Previous studies have indicated that side effects are a common patient-reported reason for discontinuing the use of statin medications [35,36]. A greater number of younger patients reported the discontinuation of betablockers due to feeling worse or not believing the medication was helping compared with the older age group. Various reports have indicated reduced adherence to beta-blockers use based on side effects, including sexual dysfunction [37], depression, and fatigue [38], which may be more notable in the younger group. Regardless of whether a patient's perception of medication-induced side effects is objective and causal or a consequence of heightened awareness, it is important to address these concerns equally because patient perception, and not reality, leads to the underuse of recommended medications. Although 
younger patients in this study see physicians on a more regular basis, in an overtaxed health care system in which clinicians see a large volume of patients without resources to meet individual patient needs, the amount of time a clinician spends with a patient may be insufficient to properly assess and understand his medication-taking behaviors [24]. Thus, it is critical that adverse effect profiles are considered when prescribing medications and are discussed with the patient before the initial prescription and at every visit thereafter.

Several limitations must be considered in interpreting the results of the present study. The most significant limitation is that our study sample had a strong local geographical limitation. We also had a small study population, and our participants were recruited from a single center with a stable population. Although this factor may limit the generalizability of results to the wider Chinese population, the findings are likely to accurately reflect the situations within urban centers. Second, our study relied on patients' self-reported medication use. Self-report measures can be biased by inaccurate patient recall or by social desirability, whereby patients report an overly optimistic estimation of medication use to their health providers. However, investigations that have used self-reporting to assess medication use have proven to be reliable and correlate well with pill count and electronic pill bottle monitoring $[9,39]$. Third, we excluded very old patients from our study population because patients older than 85 years of age were substantially less likely to receive these recommended medications than younger patients. Indeed, specific evidence regarding the efficacy and cost-effectiveness of the study medications in very old patients is lacking. In general, old patients have been excluded from participating in all efficacy trials in which current clinical practice recommendations are based. Ultimately, the categorization of younger or older patients based on an age less than 65 years of age versus 65 years of age and older is arbitrary. Although there are commonly used definitions of old age, no general agreement on the age at which a person is considered old exists. Fourth, we cannot provide insight into post-discharge actions, such as prescribing recommended medications during a subsequent outpatient visit. However, a key message that emerges from a previous report is that the extent to which the medicinetaking behavior of individuals is influenced by physicians is substantial [40]. Existing research suggests that adherence to cardiac medications is improved by complete hospital discharge recommendations, particularly if physicians encourage their patients to obtain their medications and provide drug counseling [41,42]. Fifth, we did not assess specific contraindications to medications; we only assessed the use of a specific medication if it was prescribed at discharge, suggesting that the patients were chronically taking the medications. Finally, although every effort was made to obtain information for all patients at the time of follow-up, information was available for only $81 \%$ of the patients. The limitations of this study must be considered when interpreting the results.

\section{Conclusions}

At least one year after ACS hospital discharge, the underuse of medications in elderly patients is related to low education level, comorbidities, and a high total number of discharge medications; in younger patients, it is related to low-income levels and depression. The findings of the present study can be used to guide the development of age-related strategies to improve medication use for secondary prevention among CHD patients.

\section{Abbreviations}

CHD: Coronary heart disease; ACS: Acute coronary syndrome;

ACEl: Angiotensin-converting enzyme inhibitor; ARB: Angiotensin II receptor blocker; PHQ: Patient health questionnaire; AHA: American Heart Association.

\section{Competing interests}

The authors declare that they have no competing interests.

\section{Authors' contributions}

$\mathrm{HJ}$ was the principal investigator and participated in designing the study, analyzing the data, and writing the manuscript. CCT, QW, LC, and QS contributed to the data collection. NFL and GSM provided expertise in the research design and plan coordination. All authors read and approved the final manuscript.

\section{Acknowledgments}

This study was supported by the Science and Technology Support Social Development Research Fund, a division of the Health Bureau of Jiangsu Province Government (grant no. BE2011793).

Received: 25 November 2013 Accepted: 19 September 2014 Published: 24 September 2014

\section{References}

1. Zhang XH, Lu ZL, Liu L: Coronary heart disease in China. Heart 2008, 94(9):1126-1131.

2. Critchley J, Liu J, Zhao D, Wei W, Capewell S: Explaining the increase in coronary heart disease mortality in Beijing between 1984 and 1999. Circulation 2004, 110(10):1236-1244

3. Niu S, Zhao D, Zhu J, Liu J, Liu Q, Liu J, Wang W, Smith SC Jr: The association between socioeconomic status of high-risk patients with coronary heart disease and the treatment rates of evidence-based medicine for coronary heart disease secondary prevention in China: Results from the Bridging the Gap on CHD Secondary Prevention in China (BRIG) Project. Am Heart J 2009, 157(4):709-715. e1.

4. Yang Z, Olomu A, Corser W, Rovner DR, Holmes-Rovner M: Outpatient medication use and health outcomes in post-acute coronary syndrome patients. Am J Manag Care 2006, 12(10):581-587.

5. Setoguchi S, Glynn RJ, Avorn J, Mittleman MA, Levin R, Winkelmayer WC: Improvements in long-term mortality after myocardial infarction and increased use of cardiovascular drugs after discharge: a 10-year trend analysis. J Am Coll Cardiol 2008, 51(13):1247-1254.

6. Smith SC Jr, Allen J, Blair SN, Bonow RO, Brass LM, Fonarow GC, Grundy SM, Hiratzka L, Jones D, Krumholz HM, Mosca L, Pearson T, Pfeffer MA, Taubert KA: AHA/ACC guidelines for secondary prevention for patients with coronary and other atherosclerotic vascular disease: 2006 update endorsed by the National Heart, Lung, and Blood Institute. J Am Coll Cardiol 2006, 47(10):2130-2139.

7. DeWilde S, Carey IM, Richards N, Whincup PH, Cook DG: Trends in secondary prevention of ischaemic heart disease in the UK 19942005 : use of individual and combination treatment. Heart 2008, 94(1):83-88. 
8. Smith SC Jr, Allen J, Blair SN, Bonow RO, Brass LM, Fonarow GC, Grundy SM, Hiratzka L, Jones D, Krumholz HM, Mosca L, Pasternak RC, Pearson T, Pfeffer MA, Taubert KA: AHA/ACC guidelines for secondary prevention for patients with coronary and other atherosclerotic vascular disease: 2006 update: endorsed by the National Heart, Lung, and Blood Institute. Circulation 2006 113(19):2363-2372.

9. Ho PM, Bryson CL, Rumsfeld JS: Medication adherence: its importance in cardiovascular outcomes. Circulation 2009, 119(23):3028-3035.

10. Wright RS, Anderson JL, Adams CD, Bridges CR, Casey DE Jr, Ettinger SM, Fesmire FM, Ganiats TG, Jneid H, Lincoff AM, Peterson ED, Philippides GJ, Theroux P, Wenger NK, Zidar JP, Jacobs AK: 2011 ACCF/AHA Focused Update of the Guidelines for the Management of Patients With Unstable Angina/ Non-ST-Elevation Myocardial Infarction (Updating the 2007 Guideline): a report of the American College of Cardiology Foundation/ American Heart Association Task Force on Practice Guidelines. Circulation 2011, 123(18):2022-2060

11. Kushner FG, Hand M, Smith SC Jr, King SB 3rd, Anderson JL, Antman EM, Bailey SR, Bates ER, Blankenship JC, Casey DE Jr, Green LA, Hochman JS, Jacobs AK, Krumholz HM, Morrison DA, Ornato JP, Pearle DL, Peterson ED, Sloan MA, Whitlow PL, Williams DO: 2009 focused updates: ACC/AHA guidelines for the management of patients with ST-Elevation Myocardial Infarction (updating the 2004 Guideline and 2007 Focused Update) and ACC/ AHA/SCAI Guidelines on Percutaneous Coronary Intervention (updating the 2005 Guideline and 2007 Focused Update): a report of the American College of Cardiology Foundation/American Heart Association Task Force on Practice Guidelines. Circulation 2009, 120(22):2271-2306.

12. Ho PM, Spertus JA, Masoudi FA, Reid KJ, Peterson ED, Magid DJ, Krumholz HM, Rumsfeld JS: Impact of medication therapy discontinuation on mortality after myocardial infarction. Arch Intern Med 2006, 166(17):1842-1847.

13. Newby LK, LaPointe NM, Chen AY, Kramer JM, Hammill BG, DeLong ER, Muhlbaier LH, Califf RM: Long-term adherence to evidence-based secondary prevention therapies in coronary artery disease. Circulation 2006, 113(2):203-212.

14. Ho PM, Magid DJ, Shetterly SM, Olson KL, Maddox TM, Peterson PN, Masoudi FA, Rumsfeld JS: Medication nonadherence is associated with a broad range of adverse outcomes in patients with coronary artery disease. Am Heart J 2008, 155(4):772-779.

15. Gislason GH, Rasmussen JN, Abildstrom SZ, Gadsboll N, Buch P, Friberg J, Rasmussen S, Kober L, Stender S, Madsen M, Torp-Pedersen C: Long-term compliance with beta-blockers, angiotensin-converting enzyme inhibitors, and statins after acute myocardial infarction. Eur Heart J 2006, 27(10):1153-1158.

16. Ali RC, Melloni C, Ou FS, Schmader K, Ohman EM, Roe MT, Peterson ED, Alexander KP: Age and persistent use of cardiovascular medication after acute coronary syndrome: results from medication applied and sustained over time. J Am Geriatr Soc 2009, 57(11):1990-1996.

17. Lee HY, Cooke CE, Robertson TA: Use of secondary prevention drug therapy in patients with acute coronary syndrome after hospital discharge. J Manag Care Pharm 2008, 14(3):271-280.

18. Kulkarni SP, Alexander KP, Lytle B, Heiss G, Peterson ED: Long-term adherence with cardiovascular drug regimens. Am Heart J 2006 151(1):185-191.

19. Spitzer RL, Kroenke K, Williams JB: Validation and utility of a self-report version of PRIME-MD: the PHQ primary care study. JAMA 1999, 282(18):1737-1744.

20. Bi Y, Gao R, Patel A, Su S, Gao W, Hu D, Huang D, Kong L, Qi W, Wu Y, Yang Y, Turnbull F: Evidence-based medication use among Chinese patients with acute coronary syndromes at the time of hospital discharge and 1 year after hospitalization: results from the Clinical Pathways for Acute Coronary Syndromes in China (CPACS) study. Am Heart J 2009. 157(3):509-516. e1.

21. Grines CL, Bonow RO, Casey DE Jr, Gardner TJ, Lockhart PB, Moliterno DJ O'Gara P, Whitlow P: Prevention of premature discontinuation of dual antiplatelet therapy in patients with coronary artery stents: a science advisory from the American Heart Association, American College of Cardiology, Society for Cardiovascular Angiography and Interventions, American College of Surgeons, and American Dental Association, with representation from the American College of Physicians. Circulation 2007, 115(6):813-818

22. Makaryus AN, Friedman EA: Patients' understanding of their treatment plans and diagnosis at discharge. Mayo Clin Proc 2005, 80(8):991-994
23. Kripalani S, Henderson LE, Jacobson TA, Vaccarino V: Medication use among inner-city patients after hospital discharge: patient-reported barriers and solutions. Mayo Clin Proc 2008, 83(5):529-535.

24. Brown MT, Bussell JK: Medication adherence: WHO cares? Mayo Clin Proc 2011, 86(4):304-314

25. Garner JB: Problems of nonadherence in cardiology and proposals to improve outcomes. Am J Cardiol 2010, 105(10):1495-1501.

26. Libby AM, Fish DN, Hosokawa PW, Linnebur SA, Metz KR, Nair KV, Saseen JJ, Vande Griend JP, Vu SP, Hirsch JD: Patient-level medication regimen complexity across populations with chronic disease. Clin Ther 2013, 35(4):385-398. e1.

27. Mojtabai $\mathrm{R}$, Olfson M: Medication costs, adherence, and health outcomes among Medicare beneficiaries. Health Aff (Millwood) 2003, 22(4):220-229.

28. Xu L, Wang Y, Collins CD, Tang S: Urban health insurance reform and coverage in China using data from National Health Services Surveys in 1998 and 2003. BMC Health Serv Res 2007, 7:37.

29. Fang $K$, Jiang $Y$, Shia B, Ma S: Impact of illness and medical expenditure on household consumptions: a survey in western China. PLOS One 2012, 7(12):e52928.

30. Jiang W, Glassman A, Krishnan R, O'Connor CM, Califf RM: Depression and ischemic heart disease: what have we learned so far and what must we do in the future? Am Heart J 2005, 150(1):54-78.

31. Whooley MA: Depression and cardiovascular disease: healing the broken-hearted. JAMA 2006, 295(24):2874-2881.

32. Gehi A, Haas D, Pipkin S, Whooley MA: Depression and medication adherence in outpatients with coronary heart disease: findings from the Heart and Soul Study. Arch Intern Med 2005, 165(21):2508-2513.

33. Rieckmann N, Kronish IM, Haas D, Gerin W, Chaplin WF, Burg MM, Vorchheimer D, Davidson KW: Persistent depressive symptoms lower aspirin adherence after acute coronary syndromes. Am Heart J 2006, 152(5):922-927.

34. Bauer LK, Caro MA, Beach SR, Mastromauro CA, Lenihan E, Januzzi JL, Huffman JC: Effects of depression and anxiety improvement on adherence to medication and health behaviors in recently hospitalized cardiac patients. Am J Cardiol 2012, 109(9):1266-1271.

35. Ali R, Alexander KP: Statins for the primary prevention of cardiovascular events in older adults: a review of the evidence. Am J Geriatr Pharmacother 2007, 5(1):52-63.

36. McGinnis B, Olson KL, Magid D, Bayliss E, Korner EJ, Brand DW, Steiner JF: Factors related to adherence to statin therapy. Ann Pharmacother 2007, 41(11):1805-1811.

37. Cook SC, Arnott LM, Nicholson LM, Cook LR, Sparks EA, Daniels CJ: Erectile dysfunction in men with congenital heart disease. Am J Cardiol 2008, 102(12):1728-1730.

38. Diaz A, Tardif JC: Heart rate slowing versus other pharmacological antianginal strategies. Adv Cardio/ 2006, 43:65-78.

39. Gehi AK, Ali S, Na B, Whooley MA: Self-reported medication adherence and cardiovascular events in patients with stable coronary heart disease: the heart and soul study. Arch Intern Med 2007, 167(16):1798-1803.

40. Rashid MA, Edwards D, Walter FM, Mant J: Medication taking in coronary artery disease: a systematic review and qualitative synthesis. Ann Fam Med 2014, 12(3):224-232

41. Eagle KA, Kline-Rogers E, Goodman SG, Gurfinkel EP, Avezum A, Flather MD, Granger CB, Erickson S, White K, Steg PG: Adherence to evidence-based therapies after discharge for acute coronary syndromes: an ongoing prospective, observational study. Am J Med 2004, 117(2):73-81.

42. Lappe JM, Muhlestein JB, Lappe DL, Badger RS, Bair TL, Brockman R, French TK, Hofmann LC, Horne BD, Kralick-Goldberg S, Nicponski N, Orton JA, Pearson RR, Renlund DG, Rimmasch H, Roberts C, Anderson JL: Improvements in 1-year cardiovascular clinical outcomes associated with a hospital-based discharge medication program. Ann Intern Med 2004, 141(6):446-453.

doi:10.1186/1471-2261-14-127

Cite this article as: Jin et al.: Age-related differences in factors associated with the underuse of recommended medications in acute coronary syndrome patients at least one year after hospital discharge. BMC Cardiovascular Disorders 2014 14:127. 